\title{
Employment Loss in Informal Settlements during the Covid-19 Pandemic: Evidence from Chile
}

\author{
Diego Gil (D) Patricio Domínguez • \\ Eduardo A. Undurraga $\cdot$ Eduardo Valenzuela
}

Accepted: 20 August 2021 / Published online: 18 October 2021

(C) The New York Academy of Medicine 2021

\begin{abstract}
The Covid-19 pandemic has reached almost every corner of the world. Despite the historical development, approval, and distribution of vaccines in some countries, non-pharmaceutical interventions will remain an essential strategy to control the pandemic until a substantial proportion of the population has immunity. There is increasing evidence of the devastating social and economic effects of the pandemic, particularly on vulnerable communities. Individuals living in urban informal settlements are in a structurally disadvantaged position to cope with a health crisis such as the Covid19 pandemic. Estimates of this impact are needed to
\end{abstract}

Supplementary Information The online version contains supplementary material available at https://doi. org/10.1007/s11524-021-00575-6.

D. Gil $(\varangle) \cdot$ E. A. Undurraga $\cdot$ E. Valenzuela Escuela de Gobierno, Pontificia Universidad Católica de Chile, Av. Vicuña Mackenna 4860, Macul CP, 7820436 Santiago, Region Metropolitana, Chile e-mail: diego.gil@uc.cl

\section{P. Domínguez}

Departamento de Ingeniería Industrial y de Sistemas, Pontificia Universidad Católica de Chile, Av. Vicuña Mackenna 4860, Macul CP, Region Metropolitana 7820436 Santiago, Chile

E. A. Undurraga

Millennium Nucleus for the Study of the Life Course and Vulnerability, Av. Vicuña Mackenna 4860, Macul CP,

7820436 Santiago, Region Metropolitana, Chile inform and prioritize policy decisions and actions. We study employment loss in informal settlements before and during the Covid-19 pandemic in Chile, using a longitudinal panel study of households living in Chile's informal settlements before and during the health crisis. We show that before the pandemic, $75 \%$ of respondents reported being employed. There is a decrease of 30 and 40 percentage points in May and September 2020, respectively. We show that the employment loss is substantially higher for individuals in informal settlements than for the general population and has particularly affected the immigrant population. We also show that the pandemic has triggered neighborhood cooperation within the settlements and that targeted government assistance programs have reached these communities in a limited way. Our results suggest that individuals living

\section{E. A. Undurraga}

Research Center for Integrated Disaster Risk Management (CIGIDEN), Av. Vicuña Mackenna 4860, Macul CP, 7820436 Santiago, Region Metropolitana, Chile

\section{E. A. Undurraga}

CIFAR Azrieli Global Scholars Program, CIFAR, Toronto, ON M5G 1M1, Canada

E. Valenzuela Instituto de Sociología, Pontificia Universidad Católica de Chile, Av. Vicuña Mackenna 4860, Macul CP, 7820436 Santiago, Region Metropolitana, Chile 
in informal settlements are facing severe hardship as a consequence of the pandemic. In addition to providing much-needed support, this crisis presents a unique opportunity for long-term improvements in these marginalized communities.

Keywords Covid-19 $\cdot$ Informal settlements · Poverty $\cdot$ Employment $\cdot$ Spatial inequalities

\section{Introduction}

The world is experiencing a major health and social crisis caused by the Covid-19 pandemic [1]. As of March 16, 2021, approximately 120 million cases and 2.7 million deaths have been reported worldwide [2]. Governments have implemented regulations and guidelines to control social behavior and prevent the spread of the virus [3-5]. Despite ongoing mass Covid-19 vaccination campaigns in several countries [6-8], non-pharmaceutical interventions will remain an essential strategy to control the pandemic in many countries until a substantial proportion of the population has immunity. There is dramatic evidence of the social and economic effects of the pandemic and public health strategies to control virus transmission on the general population [9-14]. Moreover, the pandemic does not affect every social group in the same way. Studies suggest that the health crisis has amplified existing racial, ethnic, gender, and socioeconomic disadvantages [15-19].

Individuals living in informal settlements (often called "slums") are in a structurally disadvantaged position to cope with a health crisis such as the Covid19 pandemic [20-24]. Around one billion people live in an informal settlement in the Global South, a number that has massively increased in the past decades [25-27]. Their emergence and persistence respond to social, economic, and political dynamics of the cities that host these communities [28-30]. Informal settlements typically host vulnerable populations in precarious housing conditions, without tenure security, with insufficient access to essential services [31].

The labor, urban, and social conditions typically present in informal settlements may cause its residents to be disproportionally affected during the Covid-19 pandemic. This crisis has the potential to exacerbate spatial inequalities represented by these communities. For instance, governments in many countries have imposed strict lockdown and stay-at-home orders [3, 4, 32, 33]. Many individuals in informal settlements have informal, precarious jobs, irregular income, no savings, and depend on daily earnings [34-36]. Most governments have also made individual-level behavioral recommendations, including keeping physical distance, washing hands frequently, and using face masks. Many of these regulations assume people live in adequate housing conditions, with sufficient living space and access to essential services, such as clean water and sanitation. Those conditions are often not present in informal settlements [31, 37, 38]. Residents of informal settlements frequently develop strong social networks to share social and economic resources and access public and private services [39, 40]. During a health crisis, such as the Covid-19 pandemic, social interaction and collaboration possibilities are substantially reduced.

The Ministry of Health reported the first Covid-19 case in Chile on March 3, 2020, and several epidemic control measures quickly followed [41]. Less than 3 weeks following the first reported case, the government had announced the closure of schools and universities, national night curfews, border controls, closure of non-essential businesses, and a strategy of localized lockdowns starting March 22 in seven municipalities. In mid-May, Greater Santiago ( 40\% of the Chilean population) was put under lockdown, and by mid-June, half the population in Chile was under lockdown [41]. Research suggests that these mitigation strategies significantly slowed down epidemic growth [42] and produced a significant drop in mobility and economic activity $[9,43]$. The reduction in economic activity does not affect all social groups in the same way. There is increasing evidence of the devastating social and economic effects of the pandemic, particularly on vulnerable communities [15, 19]. Estimates of this impact are needed to inform and prioritize policy decisions and actions. This calls for research on the impact on vulnerable populations.

In this paper, we study employment loss in informal settlements before and during the Covid-19 pandemic in Chile. We center our analysis on this dimension to estimate the economic burden caused by the current health crisis on these vulnerable communities. We also explore some mitigation strategies that may alleviate the economic situation of households living in these places, particularly whether this crisis has triggered neighborhood cooperation, and whether 
households living in informal settlements have had access to government assistance programs. Overall, we find that the pandemic has worsened the economic deprivation of informal dwellers; without action, this may result in a long-term poverty trap for years to come.

\section{Informal Settlements in Chile}

Compared to other Latin American countries, Chile has a small number of informal settlements. According to a cadaster conducted by the Ministry of Housing and Urbanism (MHU) in 2019 [44], there are 802 informal settlements in Chile with 47,050 households. However, there is evidence that the number of settlements has rapidly increased in the pandemic [45]. The MHU defines these places as "precarious settlements of eight or more households that inhabit on a piece of land that they possess irregularly, without at least one of three basic services (electricity, water, and sewer), and where all the housing units composed a defined social and territorial unity" [44]. Seventy-three percent of all informal settlements in Chile are located in urban areas. The number of these communities has been growing in the last decade, from 657 in 2011 to 802 in 2019 [44]. Most of this increase has occurred in the country's northern region, probably explained by an accelerated migration from neighboring countries. Immigrants head about $30 \%$ of all households living in the settlements. The proportion is substantially higher, above $50 \%$, in Chile's three northernmost regions. In these regions, the majority of immigrants in informal settlements are from neighboring Peru and Bolivia. In settlements from other regions in Chile, immigrants come from various Latin American countries, mainly Colombia, Venezuela, Haiti, Ecuador, and the Dominican Republic [44].

Chile has implemented an expansive housing policy in the last decades to reduce the country's housing deficit [46, 47]. Through these programs, thousands of families have relocated from informal settlements to low-income housing projects. In these projects, built by the private sector and financed through public subsidies, eligible lowincome households become owners of a dwelling unit, which has to comply with minimum quality standards, including formal access to basic services and public infrastructure. Access to formal housing involves a dramatic change in the quality of life of low-income families. These families no longer face the risk of eviction, live in better material conditions, and have formal access to basic utilities [48]. From a quantitative perspective, the success of the policy regime implemented is clear. However, many of these housing projects are located in the periphery of urban areas. This location has reinforced the pattern of social segregation and urban inequality that many cities face [49-51].

Although Chile has provided massive access to formal housing in the past decades [40], the number of informal settlements has been growing [52] This growth, particularly in the north of Chile, may be partly explained by a growing influx of low-income migration from neighboring countries. Another reason relates to the dramatic increase in the price of urban land in many Chilean cities, making the government's subsidies ineffective [52]. Housing quality and location have become increasingly important for families living in informal settlements [40]. Recent studies suggest that for some essential dimensions of urban welfare, households living in informal settlements have access to a better geography of opportunities than those living in low-income housing projects, despite not having property titles on their units and living in precarious housing conditions $[53,54]$. These improved opportunities may reveal a mismatch between the government's housing options for the low-income population and the actual expectations of those seeking access to formal housing.

\section{Data and Methods}

We collected data in collaboration with TechoChile (Techo). Techo is a non-profit international organization working with communities living in urban informal settlements in Latin America. The organization works with volunteers and communities building emergency homes, empowering community leaders, and supporting community-based projects [55]. Techo implements regular surveys to characterize and understand the settlements in which they work. 
Our analysis is based on a three-wave longitudinal panel study of households living in Chile's informal settlements. The baseline survey was conducted in person by Techo in September 2019. The surveys' objective was to collect relevant sociodemographic information on all households living in all the informal settlements where this NGO is working, primarily communities located in the country's biggest cities. The original target population was around 10,000 households, corresponding to a quarter of families living in informal settlements when the survey was applied. They obtained data from 5,622 households' heads on different dimensions of their life in the settlements. ${ }^{1}$ We conducted two telephone follow-up surveys with a representative random subsample of the individuals interviewed at baseline. We stratified the subsample according to three criteria: regional area (north, center, and south), age, and gender. We randomly selected replacements following the sample stratification when the original individual did not respond to several contact attempts. The second and third waves were conducted in May $(n=990$ households) and September ( $n=703$ households). Table A2(Supplementary Material) examines the balance of observable characteristics across waves. Based on the information collected in the baseline survey of September 2019, Table A2 shows that according to many relevant observable characteristics, there are no statistically significant differences between the sample surveyed in 2020 and the whole population measured in 2019.

We analyze the evolution over time, before and during the Covid-19 pandemic, of outcomes related to employment status, cooperation among neighbors, and government assistance. All surveys were answered by the head of the household. Employment status refers to whether the respondent had worked for pay during the week before the survey in the formal or informal sector. Cooperation among neighbors refers to whether respondents have offered help to their neighbors (listening to problems, domestic work, lending money, in-kind support, child care). Government assistance refers to whether the households

\footnotetext{
1 Endnotes.

See supplementary material Table A1 that describes the location of individuals surveyed in 2019, relative to the sample of slums identified in each Chilean region, according to government official records.
}

had received support from government programs to mitigate the economic impact of the pandemic (see Tables S3 for variable definitions and S4 for descriptive statistics across panel waves).

To quantify the changes in a set of outcomes over time, we exploit the individual-level panel data to analyze how each outcome has changed over time. We estimate Eq. (1) as follows:

$y_{i t}=\alpha+\beta_{1}$ Post $_{1}+\beta_{2}$ Post $_{2}+\gamma_{i}+\epsilon_{i t}$

where $y_{i t}$ represents the outcome of interest $y$ for individual $i$ at time $t(\mathrm{t}=0,1,2)$. We run a separate regression analysis for each outcome on a dataset that contains information on respondents who were surveyed three times between September 2019 and September 2020. $\beta_{1}$ and $\beta_{2}$ are our coefficients of interest and represent - relative to our 2019 baseline surveythe change in the outcome observed in May and September 2020, respectively. In many specifications, we include an individual fixed effect term $\left(\gamma_{i}\right)$ that controls for all individual time-invariant characteristics that may affect the outcomes. We examine the robustness of results to other specifications and to the inclusion of individual and other types of fixed effects (e.g., community fixed effects). Finally, $\epsilon_{i t}$ is the error term associated with each particular outcome $(y)$ and individual $i$ in the period of observation $t$. In short, by running separate regressions, Eq. (1) allows us to describe the evolution over time of outcomes related to employment status, cooperation among neighbors, and government assistance. We included survey weights in most regression specifications, which allow us to interpret our findings as representative of the original sample of households living in informal settlements.

For employment status, we examine the magnitude of the results relative to other employment surveys. The best comparison group that may offer a reasonable benchmark to examine the specific change in employment among informal dwellers is unclear. We compare our results to different population groups from the ENE-Survey (ENE), which is the primary employment survey run by Chile's National Institute of Statistics, and which uses a sample that is representative of the whole Chilean population. We exploit individual microdata to examine the employment 
evolution during the same period. ${ }^{2}$ We examine whether results are driven by some underlying conditions related to informal dwellers that make them particularly vulnerable to the type of crisis triggered by the Covid-19 pandemic.

All statistical analyses were done using Stata, version 15, StataCorp. The study was approved by the Comité Ético Científico de Ciencias Sociales, Artes, y Humanidades of the Pontificia Universidad Católica de Chile (Protocol ID: 200617018).

\section{Results}

The first set of results refers to the observed changes in employment status over time; we examine their magnitude relative to other estimates obtained from the ENE survey. We find a dramatic employment loss among informal dwellers during the pandemic, larger than the effect in the general population. Table 1 summarizes the evolution of employment status. We compare coefficients under different model specifications. Columns (1) and (2) show results from a pooled cross-section model, while column (3) shows our preferred specification, including individual fixed effects. The results are remarkably robust across specifications. Post- 1 and post- 2 capture the change in employment status observed in May and September 2020, respectively, compared to the prepandemic period in September 2019. After the pandemic, labor participation in the informal settlements drops around 35 percentage points (Table 1, column 3 , post- $1 ; \beta=-035, p<0.01)$, representing a $50 \%$ drop relative to the pre-pandemic level. The decrease in September is even more considerable. Compared to September 2019, labor force participation decreases by around 40 percentage points (Table 1 , column 3 , post-2, $\beta=-0.41, p<0.01)$, from a pre-pandemic

\footnotetext{
2 Encuesta Nacional de Empleo (ENE Survey) is a monthly national survey that surveys a random sample of the Chilean household. The survey contains information of all individuals older than 15 years within a selected household, and it corresponds to the main instrument to monitor the evolution of employment, among other labor market outcomes. The sample of the survey considers approximately 12,000 households which correspond to approximately 35,000 individuals each month. The survey considers as employees those who answer with "yes" to the question if last week they worked for at least 1 hour. This survey is managed by the Chilean national Institute of Statistics (Instituto Nacional de Estadísticas, INE).
}

Table 1 Changes in employment status over time

\begin{tabular}{llll}
\hline & $(1)$ & $(2)$ & $(3)$ \\
\hline Post-1 & $-0.249 * * *$ & $-0.289 * * *$ & $-0.347 * * *$ \\
& $(0.0198)$ & $(0.0284)$ & $(0.0259)$ \\
Post-2 & $-0.392 * * *$ & $-0.405 * * *$ & $-0.409 * * *$ \\
& $(0.0188)$ & $(0.0246)$ & $(0.0220)$ \\
Constant & $0.732 * * *$ & $0.765 * * *$ & $0.782 * * *$ \\
& $(0.00594)$ & $(0.0164)$ & $(0.0127)$ \\
Observations & 6,968 & 1,865 & 1,887 \\
R-squared & 0.079 & 0.214 & 0.253 \\
Individual FE & No & No & Yes \\
Settlement FE & No & Yes & No \\
Weight & No & Yes & Yes \\
\hline
\end{tabular}

Notes: Coefficients are estimated under different model specifications. Column (1) shows the result from a pooled cross-section regression. Coefficients post- 1 and post- 2 show the change in employment status for each particular period, relative to the pre-pandemic period measured in September 2019. Column (2) reproduces the same specification as column (1) but including settlement fixed effects and weights. Column (3) shows results, including individual fixed effects, as specified in Eq. (1) and includes survey weights. Robust standard errors in parentheses. ${ }^{*} p<0.1, * * p<0.05, * * * p<0.01$

level of $75 \%$. Table A5 shows an additional robustness check using a logistic regression. The estimated employment losses are qualitatively similar to the loss shown in Table 1.

To examine the magnitude of the decrease in employment, we compare our results with the nationally representative ENE survey. The ENE sample and the sample on informal settlers represent groups that may differ across observable and unobservable attributes (Supplementary Material, Table A6), ${ }^{3}$ limiting the causal claim of the employment effects of the pandemic among individuals in an informal settlement. Our objective is to document the magnitude

\footnotetext{
3 Table A6 (Supplementary Material) compares respondents from both surveys across a key set of characteristics. Respondents differ in several observable and unobservable characteristics. For example, the proportion of women among informal dwellers is slightly higher than the subsamples in the ENE survey. Individuals in the ENE sample are older, have more years of education, and fewer immigrants. In that sense, our results for informal dwellers should be interpreted as responding to a combination of factors associated with this particular group of the population, some of them observable as described in Table A6, and others unobservable characteristics that drive the decision to reside in informal settlements.
} 
Fig. 1 Evolution of the employment rate as the proportion of individuals employed (A) and relative to pre-pandemic levels (B). The figure shows the evolution of the employment rate before and after the Covid-19 pandemic period for different survey series. Panel A shows the employment rate as the proportion of people employed divided by the population older than 15 years old on each survey. Panel B shows the employment rate evolution relative to the average level observed during the prepandemic months observed on each series. The vertical dashed line marks the beginning of the pandemic in Chile. From ENE monthly surveys, we plotted both the evolutions of the nationally representative sample and a subsample of respondents who reported less than complete secondary education and were residing in municipalities with at least one informal settlement. Information on informal dwellers was obtained from Techo-Panel Survey 2019-2020
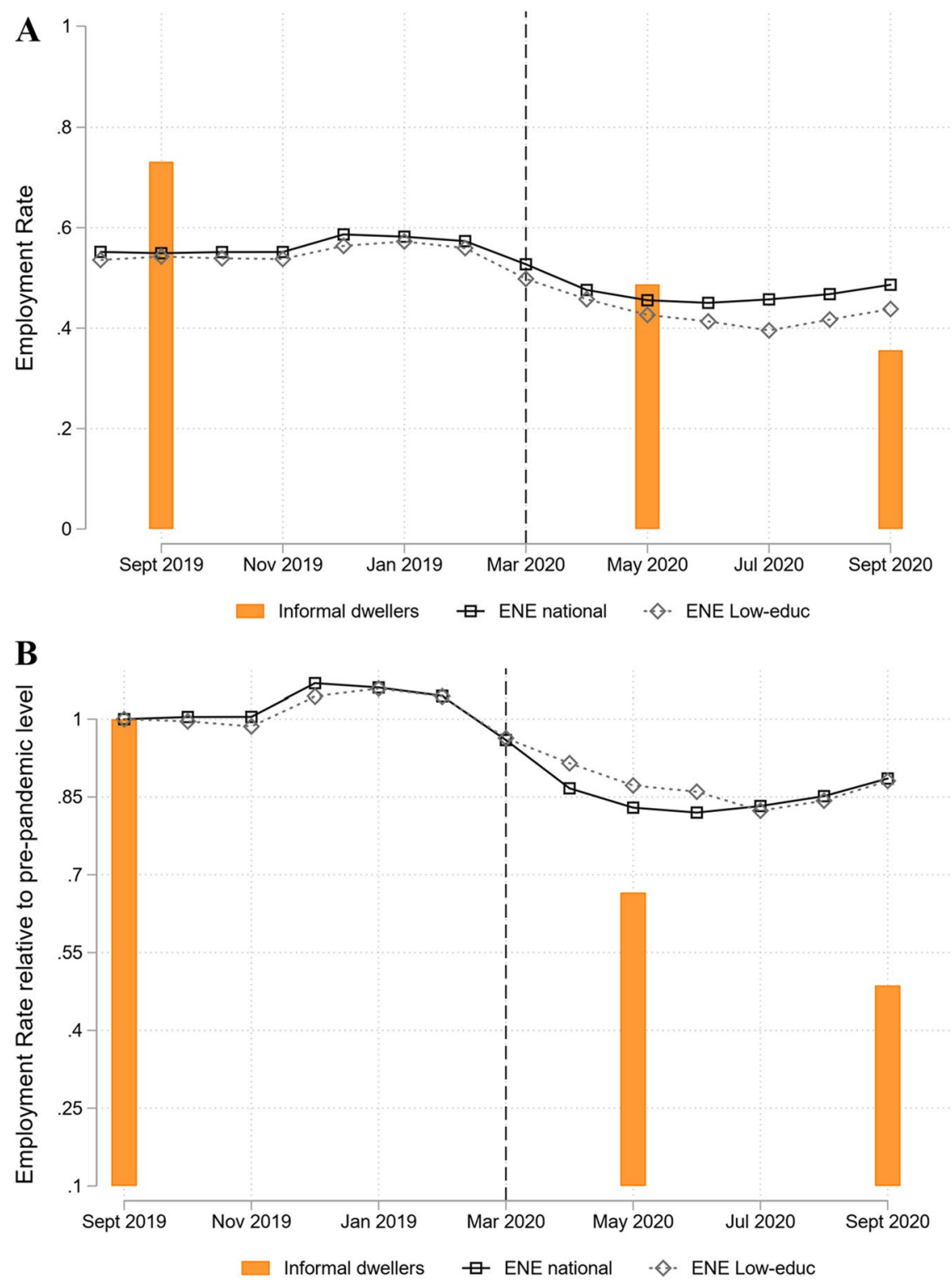

of the employment drop among individuals living in informal settlements. Therefore, we examine a reasonable benchmark. The change in employment in the general population is critical considering the extension of the economic shock induced by the Covid-19 pandemic. Given the notorious differences between informal dwellers and the general population, we also compare informal dwellers to a socioeconomically vulnerable subsample of the national population in the ENE survey. This subsample is defined by household heads with a low level of formal education living in the same municipalities where the informal settlements in our sample are located. Figure $1 \mathrm{com}-$ pares the evolution of labor participation over time for different groups: national population, individuals with incomplete formal education (less than secondary) residing in the same municipalities as our sample, and informal dwellers. We show these results in two figures. Figure 1A examines the evolution in the proportion of people employed, and Fig. 1B shows the change relative to the pre-pandemic period. Compared to the national population, informal dwellers 
exhibit, in pre-pandemic times, a higher labor market participation [56].

Figure 1 shows that relative to the national population, employment loss is larger among informal dwellers. The decrease in employment status is even more significant than for individuals with lower education levels living in the same municipalities. The corresponding drop in employment in the general population is 10 and 6 percentage points in May and September 2020, respectively. Table A7 (Supplementary Material) provides results by running a pooled cross-section regression including all available ENEseries available between September 2019 and October 2020. Coefficients are robust to various specifications when including individual controls such as gender, immigration status, age and years of formal education, and municipality fixed effects to account for differences across municipalities. Because these two groups may differ in many key attributes that can affect employment status over time, observed differences cannot be exclusively attributed to living in an informal settlement. However, we believe that this comparison can provide insights into the magnitude of the employment change relative to a more vulnerable population. Moreover, comparing individuals' trajectories in the same municipalities reduces the observed variation attributed to localized lockdowns implemented at the municipality level. These lockdowns may affect people differently, depending on the district where they live.[9]

We further examine the extent to which the larger drop in employment can be explained in terms of some observable attributes of informal dwellers that have been more affected by the pandemic at the national level. Figure 2A examines whether the large proportion of immigrants living in informal settlements may account for the larger employment loss. Figure $2 \mathrm{~B}$ shows the employment impact disaggregated by gender.

Figure 2 shows that employment loss in May 2020 was substantial among immigrants. Immigrants in both surveys display a higher employment rate before the pandemic and a dramatic loss at the beginning of the pandemic. Among immigrant respondents with incomplete secondary education from the representative national population ENE survey, the employment rate drops from 80 to $60 \%$ between February 2020 and April 2020. Informal immigrant dwellers suffered a larger drop, from 80 to $40 \%$, between September 2019 and May $2020 .^{4}$

Interestingly, after April 2020, the immigrant population from the national population survey exhibits a growing trend in employment up to approximately 65\% in September 2020. This contrasts with the employment evolution among Chilean respondents from the same survey. The employment rate drops roughly from 55\% in February 2020 to $40 \%$ in May 2020, and remains relatively stable through September 2020. Among informal dwellers, we observe a similar trend across groups with an important difference in scale. Relative to Chilean settlement dwellers, employment loss among immigrants was $15 \%$ larger in May. In September, the employment rate decreased further for both groups, up to $40 \%$; however, there was no statistically significant difference across groups. We show the estimates for these effects in columns 1 and 2, Table A8 (Supplementary Material), using individual-level panel data including heterogeneous changes by immigrant status. In other words, immigrants were more affected by unemployment than non-immigrants early on in the pandemic, but the difference leveled out in the longer term. This finding does not hinge on sampling design because the panel waves are balanced in immigrants across waves (Table A2, Supplementary Material).

There is a sharp decrease in employment status affecting women, who exhibited lower employment before the pandemic (between 11 and 9 percentage points lower than men, according to the two specifications shown in columns 4 and 5 of Table A8). The employment rate for women falls, roughly, from 73 to $43 \%$ between September 2019 and May 2020, and continues to fall through September 2020 to $30 \%$ (see column 4 in Table A8). The absolute decrease in employment status is

\footnotetext{
${ }^{4}$ While we do not observe monthly evolution of employment among informal dwellers, an obvious concern may relate to employment seasonality. Given the magnitude of the drop, seasonality seems to be a second-order issue that could affect the magnitude of the observed change. By using the same nationally representative survey during 2019, we observe a fair degree of stability over time among the national population and the subgroup of respondent with incomplete education residing in municipalities with at least one slum. See supplementary material Figure S1.
} 
Fig. 2 Employment rate evolution, by immigration status (A) and gender (B). Evolution of employment rate before and after the Covid-19 pandemic period for different survey series. We measured employment rate as the proportion of people employed divided by the population older than 15 years old on each survey. Panel A splits each sample by the respondent's immigration status, and panel B splits each sample by respondent's gender. The vertical dashed line marks the beginning of the pandemic in Chile. ENE monthly surveys show the evolution of a subsample of respondents who reported less than complete secondary education and resided in municipalities with at least one informal settlement. Information on informal dwellers was obtained from Techo-Panel Survey 2019-2020
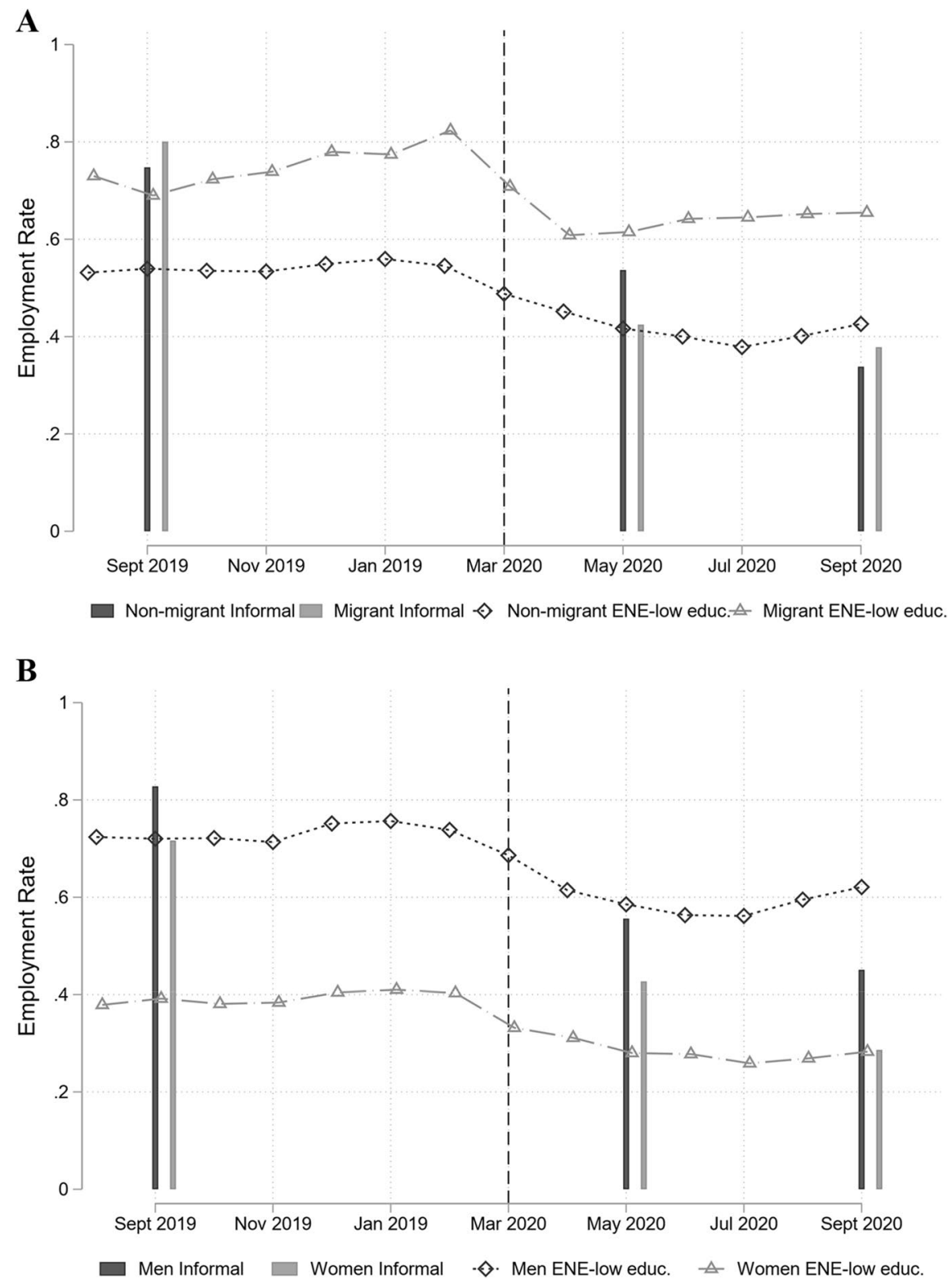

larger for women, but not statistically significant at conventional levels relative to men. Across all specifications, the magnitude of the drop in women's labor participation compared to men is between 1 and 6 percentage points. Although, in absolute terms, we do not detect statistically significant differences by gender, we highlight that the drop in employment is more dramatic for women when we compare percentage changes. For example, according to columns 4 and 5 (Table A8), the change in employment for men represent a $32 \%$ and $45 \%$ decrease during each period, while similar percentage changes relative to the baseline period for women are $39 \%$ and $59 \%$.

We also analyze changes in collaboration among neighbors (Table 2), a dimension of informal settlements' social capital, which may mitigate some of the economic hardships we have described for the informal settlements' population. The questions analyzed refer to whether respondents provide help to their neighbors in their communities. The results shown in Table 2 suggest that the pandemic has triggered social 
Table 2 Changes in collaboration with neighbors over time

\begin{tabular}{|c|c|c|c|c|c|}
\hline & (1) & (2) & (3) & (4) & (5) \\
\hline & Listens problems & Domestic work & Money & Clothes and food & $\begin{array}{l}\text { Child } \\
\text { care }\end{array}$ \\
\hline \multirow[t]{2}{*}{ Post-1 } & 0.0288 & $0.243 * * *$ & 0.00410 & $0.123 * * *$ & $0.169 * * *$ \\
\hline & $(0.0247)$ & $(0.0253)$ & $(0.0251)$ & $(0.0236)$ & $(0.0247)$ \\
\hline \multirow[t]{2}{*}{ Post-2 } & $0.0481 *$ & $0.193 * * *$ & $-0.0559 * *$ & $0.0781 * * *$ & $0.0578 * *$ \\
\hline & $(0.0250)$ & $(0.0258)$ & $(0.0243)$ & $(0.0248)$ & $(0.0250)$ \\
\hline \multirow[t]{2}{*}{ Constant } & $0.640 * * *$ & $0.399 * * *$ & $0.358 * * *$ & $0.658 * * *$ & $0.326 * * *$ \\
\hline & $(0.0144)$ & $(0.0149)$ & $(0.0144)$ & $(0.0143)$ & $(0.0142)$ \\
\hline Observations & 2,088 & 2,089 & 2,090 & 2,083 & 2,083 \\
\hline R-squared & 0.003 & 0.073 & 0.006 & 0.021 & 0.035 \\
\hline Individual FE & Yes & Yes & Yes & Yes & Yes \\
\hline Number of id & 703 & 703 & 703 & 703 & 703 \\
\hline
\end{tabular}

Notes: The table shows coefficients for different outcomes as specified in each column. Each outcome variable is measured as an indicator variable for whether the respondent "collaborates with his/her neighbors on" issues identified by each column. Variable definitions are available in the Supplementary Material, Table A3. Coefficients were estimated under different model specifications as indicated in the lower panel. All coefficients are estimated survey weights. Coefficients are estimated using Eq. (1), and all regressions include individual fixed effects. Robust standard errors in parentheses. $* p<0.1, * * p<0.05$, *** $p<0.01$

collaboration among neighbors, particularly with respect to helping with domestic work, clothes and food, and child care assistance. However, we detect a deterioration between May and September 2020 in the proportion of respondents who report helping neighbors on these items (Table 2, columns 2, 4, and 5 , respectively). We do not detect significant changes in May for "listening to problems" and "lending money", but we do observe an increase in September for the former, and a decrease for the latter, relative to the pre-pandemic period.
Last, we analyze coverage of government programs implemented to reduce employment loss consequences during this period. In May and September 2020, we asked about unemployment insurance and a COVID cash transfer program ("Bono COVID") that the government designed to provide economic aid during the pandemic to vulnerable families. Through Bono COVID, the government transfers up to approximately USD70 to low-income households belonging to the first three quintiles of the income distribution who do not have income from work or pensions.

Table 3 Changes in programs participation between May and September 2020

\begin{tabular}{|c|c|c|c|c|c|c|}
\hline & (1) & (2) & (3) & (4) & (5) & (6) \\
\hline & Unemp. insurance & Unemp. insurance & Unemp. insurance & Covid transfer & Covid transfer & Covid transfer \\
\hline \multirow[t]{2}{*}{ Post-2 } & $0.112 * * *$ & $0.110 * * *$ & $0.114 * * *$ & 0.0431 & $0.0418 *$ & $0.0400 * *$ \\
\hline & $(0.0175)$ & $(0.0175)$ & $(0.0161)$ & $(0.0264)$ & $(0.0245)$ & $(0.0163)$ \\
\hline \multirow[t]{2}{*}{ Constant } & $0.0606^{* * *}$ & $0.0611 * * *$ & $0.0594 * * *$ & $0.327 * * *$ & $0.329 * * *$ & $0.329 * * *$ \\
\hline & $(0.00937)$ & $(0.00984)$ & $(0.00816)$ & $(0.0184)$ & $(0.0170)$ & $(0.00825)$ \\
\hline Observations & 1,381 & 1,363 & 1,381 & 1,387 & 1,369 & 1,387 \\
\hline R-squared & 0.030 & 0.117 & 0.074 & 0.002 & 0.211 & 0.009 \\
\hline Individual FE & No & No & Yes & No & No & Yes \\
\hline Settlement FE & No & Yes & No & No & Yes & No \\
\hline
\end{tabular}

Notes: The table shows coefficients for different outcomes as specified in each column. Each outcome variable is measured as an indicator variable for whether the respondent "receives resources from" sources identified by each column. Details about each variable definition are available in Appendix Table A1. All coefficients are estimated using survey weights. Coefficients are estimated using Eq. (1). Robust standard errors in parentheses. $* p<0.1$, ** $p<0.05$, *** $p<0.01$ 
During our study period, this cash transfer was given only once.

Table 3 shows that participation in the unemployment insurance program among informal dwellers increased from 6 to $17 \%$ between May and September 2020. An important limitation of the unemployment insurance program is the high proportion of informal workers among settlement dwellers, which makes them ineligible. About a quarter of respondents that lost employment between 2019 and 2020 claimed the unemployment insurance benefit. The Bono COVID was given to $33 \%$ of respondents in May 2020 and 37\% in September 2020..$^{5}$ Although this program's coverage was higher among those who never reported employment (56\%) or those who lost employment after the pandemic (53\%), more than half of the respondents reported not having received this benefit during the pandemic.

\section{Discussion and Policy Implications}

The Covid-19 pandemic has imposed new costs, restrictions, and risks globally. These changes affect everyone, but individuals living in informal settlements are in a particularly problematic position to cope with such a crisis. There is substantial evidence of the harmful effects of the pandemic and viral transmission control strategies, such as lockdowns and school closures, on economic activity. These effects have resulted in a substantial employment loss [10, 12, 13, 57, 58]. Residents of informal settlements are more economically vulnerable to external shocks in the economy than the general population because a

\footnotetext{
${ }^{5}$ We analyze heterogeneous responses by immigration status and gender in supplementary material Table A9. In this case, we are constrained by the fact that these questions were later incorporated in the 2020 surveys. We observe several important facts. First, while we do not detect differences between Chileans and immigrants in any of the two periods for the unemployment insurance program, differences in COVIDtransfers are substantial. In May, 2020, while $40 \%$ of Chilean informal dwellers had received the transfer, only $20 \%$ of immigrants had participated. In terms of gender, we observe that women exhibit a $16 \%$ higher participation rate in COVIDtransfer program in May 2020 and the gender gap drops by 7 percentage points in September 2020. In the case of unemployment insurance program participation, we observe no difference by gender among informal dwellers in any of the two periods of analysis.
}

large proportion performs informal jobs earning subsistence wages. Our findings are consistent with this evidence.

Our results show that there has been a dramatic drop in employment status during the pandemic for informal settlement residents compared to prepandemic times. The decline in employment status among informal dwellers has been significantly larger relative to the Chilean population. We arrive at the same conclusion if we compare our results to employment among individuals with incomplete secondary education living in the same municipalities. The economic toll imposed by the pandemic in informal settlements has been enormous. More than half of settlement dwellers have lost their income source 6 months after the first Covid-19 case was reported in Chile.

Our data allow us to explore whether the economic crisis triggered by the pandemic has affected vulnerable groups within informal settlements: immigrants and women. We find large effects among immigrants, which corresponds to $40 \%$ of our sample, early in the pandemic. Employment loss is sharper in the first 3 months, but after 6 months their diminished labor participation is similar to the one affecting Chileans living in the settlements. Many low-income immigrants come to Chile seeking social and economic opportunities. They probably find a place in an informal settlement while they regularize their migratory status, which may allow them to access to government programs and better job possibilities. The crisis puts them in a vulnerable position. We also found that immigrant households are substantially less likely to receive government assistance, such as the Bono COVID or in-kind food transfers.

Although women show lower labor participation than men before the pandemic, their decline in employment status is comparable to that of men and probably larger. Many jobs were lost as a direct effect of the pandemic and public health mitigation strategies. Women may face additional challenges. For instance, schools were closed for most of the study period. Because women are often the primary caregivers for children, their employment is probably more affected.

Although we observe some compensatory reactions that may alleviate part of the loss in employment during the period examined, the overall response during 2020 has been far from sufficient. Our results suggest that neighborhood cooperation within informal 
settlements increased at the onset of the pandemic but has decreased over time. This decrease may be an essential source of vulnerability, as individuals living in settlements often depend on local networks to access resources, including food, labor, and childcare [27].

Last, we show that the number of informal households that received government support increased during the pandemic but has reached only a fraction of the population in need. Informal settlements often attract less public assistance because they are installed on land without a proper legal title [34]. This complex relationship with governments could be more problematic during the pandemic. Communities sometimes cope with the lack of aid from government offices by developing strong social networks among neighbors and with the support of NGOs and other private institutions.

Some researchers have conceptualized informal settlements as "poverty traps," which prevent lowincome families from accumulating the economic and social resources necessary to improve their disadvantaged situation [37]. Other authors have provided a more complex picture of these communities, conceiving these urban enclaves as low-cost housing options for vulnerable individuals that aim to take advantage of the access that the settlements provide to the economic and social opportunities that a city brings [36]. Individuals in some informal urban settlements may have better access to economic and social urban opportunities - such as connectivity, jobs, social networks, and community organizations - than lowincome individuals in government-subsidized housing projects [40, 53, 54]. Urban informal settlements may be a relevant source of economic activity and income in a city and may run social, political, and cultural initiatives [40, 59, 60]. Our results suggest that individuals living in informal settlements are facing severe hardship due to the pandemic. The necessary public health measures to control the pandemic have imposed severe economic costs to vulnerable groups. Governments need to implement mitigation strategies to compensate for the economic loss suffered by severely deprived households [21]. In addition to providing much-needed support, this crisis presents a unique opportunity for long-term improvements in these marginalized communities [22]. Policies should particularly consider the informal economic sector, immigrants, and women.
Acknowledgements We thank Laura Marshall (Pontificia Universidad Católica de Chile) for outstanding research assistance with data analysis. We also want to thank the excellent work of Catalina Rufs (Pontificia Universidad Católica de Chile) in data collection and analysis. We thank the staff of Techo-Chile, and all their volunteers who worked in the implementation of this survey and the Dirección de Estudios Sociológicos UC for technical support.

Author Contribution Conceptualization and funding acquisition: DG, EU, and EV. Data curation, analysis, investigation, and methodology: DG, PD, EU, and EV. Writing original draft: DG and PD. Writing, review, and editing: DG, PD, EU, and EV.

Funding The survey used in this paper was funded partially by TECHO-Chile and the School of Social Sciences of Pontificia Universidad Católica de Chile. This work was also partially supported by the ANID Millennium Science Initiative NCS17_062 and Research Center for Integrated Disaster Risk Management (CIGIDEN), ANID FONDAP 15110017. The study sponsors had no role in the study design, collection, analysis, and interpretation of data, in the writing of the manuscript, and in the decision to submit the manuscript for publication.

\section{Declarations}

Ethics Approval and Consent to Participate The study was approved by the Comité Ético Científico de Ciencias Sociales, Artes, y Humanidades of the Pontificia Universidad Católica de Chile (Protocol ID: 200617018). We obtained participant's informed consent by telephone, to avoid the risk of Covid-19 contagion.

\section{References}

1. Zhu N, Zhang D, Wang W, et al. A novel coronavirus from patients with pneumonia in China, 2019. $N$ Engl $J$ Med. 2020;382:727-733.

2. Dong E, Du H, Gardner L. An interactive web-based dashboard to track COVID-19 in real time. Lancet Infect Dis. 2020;20(5):P533-4.

3. Flaxman S, Mishra S, Gandy A, et al. Estimating the effects of non-pharmaceutical interventions on COVID-19 in Europe. Nature. 2020;584:257-61.

4. Walker PGT, Whittaker C, Watson OJ, et al. The impact of COVID-19 and strategies for mitigation and suppression in low- and middle-income countries. Science. 2020;369(6502):413-22.

5. Wiersinga WJ, Rhodes A, Cheng AC, Peacock SJ, Prescott HC. Pathophysiology, transmission, diagnosis, and treatment of coronavirus disease 2019 (COVID-19): a review. JAMA. 2020;324(8):782-93.

6. Dagan N, Barda N, Kepten E, et al. BNT162b2 mRNA Covid-19 vaccine in a nationwide mass vaccination setting. N Engl J Med. 2021;384:1414-1423 
7. Thompson MG, Burgess JL, Naleway AL, et al. Prevention and attenuation of Covid-19 with the BNT162b2 and mRNA-1273 vaccines. $N$ Engl J Med. 2021;385(4):320-9.

8. Jara A, Undurraga EA, González C, et al. Effectiveness of an inactivated SARS-CoV-2 vaccine in Chile. $N$ Engl $J$ Med. 2021;385:875-884.

9. Asahi K, Undurraga EA, Valdes R, Wagner R. The effect of COVID-19 on the economy: evidence from an early adopter of localized lockdowns. J Glob Health. 2021;11:05002.

10. Baek C, McCrory PB, Messer T, Mui P. Unemployment effects of stay-at-home orders: evidence from high frequency claims data. Review of Economics and Statistics. 2020; Online Oct30:1-72. https://doi.org/10.1162/rest_a_ 00996

11. de Girolamo G, Cerveri G, Clerici M, et al. Mental Health in the Coronavirus Disease 2019 Emergency-The Italian Response. JAMA Psychiat. 2020;77(9):974-6.

12. Gupta S, Montenovo L, Nguyen TD, et al. Effects of social distancing policy on labor market outcomes. Natl Bur Econ Res. 2020:WP27280.

13. Lozano-Rojas F, Jiang X, Montenovo L, Simon KI, Weinberg BA, Wing $\mathrm{C}$. Is the cure worse than the problem itself? Immediate labor market effects of covid-19 case rates and school closures in the US. Natl Bur Econ Res. 2020;WP27172:1-17.

14. Janssens W, Pradhan M, de Groot R, Sidze E, Donfouet HPP, Abajobir A. The short-term economic effects of COVID-19 on low-income households in rural Kenya: an analysis using weekly financial household data. World Dev. 2021;138:105280.

15. Bennett M. All things equal? Heterogeneity in policy effectiveness against COVID-19 spread in chile. World Dev. 2021;137:105208.

16. Gil M, Undurraga EA. COVID-19 Has Exposed How 'The Other Half' (Still) Lives. Bull Lat Am Res. 2020;39(S1):28-34.

17. Tai DBG, Shah A, Doubeni CA, Sia IG, Wieland ML. The disproportionate impact of COVID-19 on racial and ethnic minorities in the United States. Clin Infect Dis. 2021;72(14):703-706.

18. Wenham C, Smith J, Morgan R. COVID-19: the gendered impacts of the outbreak. The Lancet. 2020;395(10227):846-8.

19. Mena GE, Martinez PP, Mahmud AS, Marquet PA, Buckee CO, Santillana M. Socioeconomic status determines COVID-19 incidence and related mortality in Santiago, Chile. Science. 2021;372(6545):eabg5298.

20. Brotherhood L, Cavalcanti T, Da Mata D, Santos C. Slums and pandemics. Available at SSRN 3665695. 2020.

21. Buckley RM. Targeting the world's slums as fat tails in the distribution of COVID-19 cases. J Urban Health. 2020;97:358-64.

22. Corburn J, Vlahov D, Mberu B, et al. Slum health: arresting COVID-19 and improving well-being in urban informal settlements. J Urban Health. 2020;97:348-57.

23. de Souza WM, Buss LF, Candido DdS, et al. Epidemiological and clinical characteristics of the COVID-19 epidemic in Brazil. Nat Hum Behav. 2020;4:856-65.

24. Patel A, Shah P. Rethinking slums, cities, and urban planning: lessons from the COVID-19 pandemic. Cities \&
Health. 2020;online 28 Jul:1-3. https://doi.org/10.1080/ 23748834.2020.1790252

25. United Nations. Sustainable Development Goal United Nations Statistics Division. Available at: https://unstats. un.org/sdgs/. Accessed August 10, 2020.

26. Alirol E, Getaz L, Stoll B, Chappuis F, Loutan L. Urbanisation and infectious diseases in a globalised world. Lancet Infect Dis. 2011;11(2):131-41.

27. Ezeh A, Oyebode O, Satterthwaite D, et al. The history, geography, and sociology of slums and the health problems of people who live in slums. The Lancet. 2017;389(10068):547-58.

28. Holland AC. Forbearance. Am Political Sci Rev. 2016;110(2):232-46.

29. Zhang Y. The credibility of slums: informal housing and urban governance in India. Land Use Policy. 2018;79:876-90.

30. Sun L, Ho P. Formalizing informal homes, a bad idea: the credibility thesis applied to China's "extra-legal" housing. Land Use Policy. 2018;79:891-901.

31. Habitat UN. World Cities Report 2016: Urbanization and Development-Emerging Futures. UN-Habitat: Publisher; 2016.

32. Haider N, Osman AY, Gadzekpo A, et al. Lockdown measures in response to COVID-19 in nine sub-Saharan African countries. BMJ Global Health. 2020;5(10):e003319.

33. Garcia PJ, Alarcón A, Bayer A, et al. COVID-19 Response in Latin America. Am J Trop Med Hyg. 2020;103(5):1765-72.

34. De Soto H. The mystery of capital: why capitalism triumphs in the West and fails everywhere else. Basic Books: New York; 2000.

35. Mitra A. Migration, livelihood and well-being: evidence from Indian city slums. Urban Stud. 2010;47(7):1371-90.

36. Turok I, Borel-Saladin J. The theory and reality of urban slums: pathways-out-of-poverty or cul-de-sacs? Urban Stud. 2018;55(4):767-89.

37. Marx B, Stoker T, Suri T. The economics of slums in the developing world. J Econ Perspect. 2013;27(4):187-210.

38. Mishra SV, Gayen A, Haque SM. COVID-19 and urban vulnerability in India. Habitat Int. 2020;103:102230.

39. Turner JC. Housing priorities, settlement patterns, and urban development in modernizing countries. J Am Inst Plann. 1968;34(6):354-63.

40. Salcedo R. The last slum: Moving from illegal settlements to subsidized home ownership in Chile. Urban Aff Rev. 2010;46(1):90-118.

41. Ministerio de Salud. Paso a Paso Nos Cuidamos. Plan de Acción Coronavirus Covid-19. Ministerio de Salud, Gobierno de Chile. Available at: https://www.gob.cl/pasoa paso/. Accessed Abril 13, 2021.

42. Tariq A, Undurraga EA, Laborde CC, et al. Transmission dynamics and control of COVID-19 in Chile, March-October, 2020. PLoS Negl Trop Dis. 2021;15(1):e0009070.

43. Alé-Chilet J, Atal JP, Dominguez-Rivera P. Activity and the incidence of emergencies: evidence from daily data at the onset of a pandemic (May 26, 2020). PIER Working Paper. 2020:20-016.

44. Ministerio de Vivienda y Urbanismo. Catastro Nacional de Campamentos. MINVU. Available at: https://www. 
minvu.cl/catastro-de-campamentos/. Accessed August 10, 2020.

45. Said C, Astudillo D. Aumentan familias albergadas en campamentos por "pandemia social." La Tercera. 2020;10:2020.

46. Simian JM. Logros y desafíos de la política habitacional en Chile. Estudios públicos. 2010;117:269-322.

47. Gil-McCawley D. Law and Inclusive urban development: lessons from Chile's enabling markets housing policy regime. Am J Comp Law. 2019;67(3):587-636.

48. Baeza F, Vergara AV, González F, et al. The Regeneración Urbana, Calidad de Vida y Salud-RUCAS project: a Chilean multi-methods study to evaluate the impact of urban regeneration on resident health and wellbeing. BMC Public Health. 2021;21(1):1-15.

49. Sabatini F, Cáceres G, Cerda J. Segregación residencial en las principales ciudades chilenas: tendencias de las tres últimas décadas y posibles cursos de acción. Eure (Santiago). 2001;27(82):21-42.

50. Tokman A. El MINVU, la política habitacional y la expansión excesiva de Santiago. In: Galetovic A, ed. Santiago. Donde estamos y hacia dónde vamos: Centro de Estudios Públicos, Santiago, 2006: 489-520.

51. Rodríguez A, Sugranyes A. "El problema de vivienda de los" "con techo." EURE (Santiago) 30, no. 91 (2004):53-65.

52. Matus C, Ramoneda A, Ruiz-Tagle J, Valenzuela F. Los campamentos en la política urbana chilena: desafíos y propuestas para abordar una problemática en crecimiento. Temas de la Agenda Pública. 2020;15(128):1-24.
53. Brain Valenzuela I, PrietoSuárez JJ, Sabatini DF. Vivir en campamentos: $i$ camino hacia la vivienda formal o estrategia de localización para enfrentar la vulnerabilidad? EURE (Santiago). 2010;36(109):111-41.

54. Celhay PA, Gil D. The function and credibility of urban slums: Evidence on informal settlements and affordable housing in Chile. Cities. 2020;99:102605.

55. Techo. We build a new world, nail by nail. Available at: https://us.techo.org/. Accessed July 1, 2021.

56. Domínguez P. Campamentos, viviendas y acceso a la ciudad para los pobres. Revista CIS. 2011;9(14):73-94.

57. Aum S, Lee SYT, Shin Y. COVID-19 Doesn't Need Lockdowns to Destroy Jobs: The Effect of Local Outbreaks in Korea. Labour Economics. 2021;70:101993.

58. World Bank. The economy in the time of CoVID-19. World Bank. Available at: https://bit.ly/35B2r3y. Accessed April, 2020.

59. Fox S. The political economy of slums: theory and evidence from Sub-Saharan Africa. World Dev. 2014;54:191-203.

60. Andrade RdO. The Brazilian slums hiring their own doctors to fight covid-19. BMJ. 2020;369:m1597.

Publisher's Note Springer Nature remains neutral with regard to jurisdictional claims in published maps and institutional affiliations. 